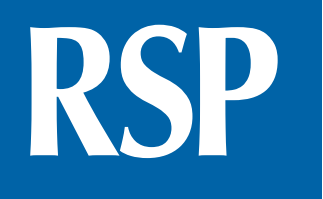

http://www.rsp.fsp.usp.br/
Revista de Saúde Pública

\title{
Dietary patterns of pregnant women, maternal excessive body weight and gestational diabetes
}

\author{
Daniela Cristina Candelas Zuccolotto' (iD, Lívia Castro Crivellenti' iD, Laércio Joel Franco"I iD, \\ Daniela Saes Sarotelli" iD \\ ' Universidade de São Paulo. Faculdade de Medicina de Ribeirão Preto. Programa de Pós-Graduação em Saúde \\ Pública. Ribeirão Preto, SP, Brasil \\ " Universidade de São Paulo. Faculdade de Medicina de Ribeirão Preto. Departamento de Medicina Social. \\ Ribeirão Preto, SP, Brasil
}

\section{ABSTRACT}

OBJECTIVE: To investigate the relationship between the dietary patterns of pregnant women with maternal excessive body weight and gestational diabetes mellitus .

METHODS: A cross-sectional study conducted with a convenience sample of 785 adult pregnant women attended by the Unified Health System of Ribeirão Preto, state of São Paulo, between 2011 and 2012. Two 24-hour dietary recalls, corrected by the multiple source method, were employed. For the classification of the body mass index and the diagnosis of gestational diabetes mellitus, the criteria by Atalah and the World Health Organization were used, respectively. Dietary patterns were obtained by principal component analysis using the Varimax rotation method. The relationship between adherence to patterns, overweight and obesity was analyzed by multinomial logistic regression models and the relationship with gestational diabetes mellitus by adjusted unconditional logistic regression models.

RESULTS: We identified four dietary patterns: "traditional Brazilian"; "snacks"; "coffee" and "healthy". Women with a higher adherence to the "Healthy" (OR $=0.52 ; 95 \% \mathrm{CI} 0.33-0.83)$ and

Correspondence:

Daniela Saes Sartorelli

Avenida Bandeirantes, 3900

14049-900 Ribeirão Preto, SP, Brasil

E-mail: daniss@fmrp.usp.br

Received: Apr 27, 2018

Approved: Sep 27, 2018

How to cite: Zuccolotto DCC, Crivellenti LC, Franco LJ, Sarotelli DS. Dietary patterns of pregnant women, maternal excessive body weight and gestational diabetes. Rev Saude Publica. 2019;53:52.

Copyright: This is an open-access article distributed under the terms of the Creative Commons Attribution License, which permits unrestricted use, distribution, and reproduction in any medium, provided that the original author and source are credited.
"Brazilian Traditional" patterns $(\mathrm{OR}=0.61$; 95\%CI 0.38-0.96) presented a lower chance of obesity, when compared to women with lower adherence, regardless of confounding factors. After adjustment for maternal excessive body weight, there was no association between dietary patterns and gestational diabetes mellitus.

CONCLUSIONS: Among the pregnant women, greater adherence to "traditional Brazilian" and "healthy" patterns was inversely associated with obesity, but no relationship was identified with gestational diabetes mellitus after adjusting for excessive body weight. Prospective studies are recommended to investigate the relationship between dietary patterns, overweight and gestational diabetes mellitus, reducing the chance of reverse causality.

DESCRIPTORS: Pregnant Women. Gestational Diabetes. Feeding Behavior. Risk Factors. Prenatal Nutrition. 


\section{INTRODUCTION}

Gestational diabetes mellitus (GDM), a hyperglycemia diagnosed for the first time during pregnancy, is the most common metabolic problem during pregnancy $y^{1}$. Its prevalence has been growing substantially ${ }^{2}$ and projections suggest this increase will go on further given the expansion in the number of cases of excessive body weight among women of reproductive age $^{3}$. The GDM can trigger the development of obstetric complications and losses to maternal and child health in the short and long term ${ }^{4,5}$. Thus, the identification of modifiable risk factors related to the genesis of the disease is extremely relevant.

Certain studies indicate that both nutrient and food intake alone and adherence to dietary patterns are directly related to the health of the mother-child binomial ${ }^{3,6}$. However, the approach of eating patterns is recognized as more comprehensive, considering the synergistic and inhibitory action of the simultaneous consumption of different foods and their relationship with health outcomes ${ }^{7,8}$.

In addition to being scarce, studies that evaluated the relationship between dietary patterns during gestation and GDM show inconsistent findings due to distinct characteristic of food cultures seen among the populations analyzed ${ }^{9-11}$. In a study conducted in China with 3063 pregnant women, higher adherence to the "sweet and seafood" pattern was directly associated with $\mathrm{GDM}^{9}$. On the other hand, Seymor et al. ${ }^{10}$, when analyzing the dietary pattern of 909 pregnant women in Singapore, identified that adherence to the diet pattern based on seafood and pasta was inversely associated with the disease ${ }^{10}$. The divergence in the results indicates that more studies should be conducted in order to elucidate the role of maternal diet in the occurrence of GDM, especially in regions with different eating behaviors.

In view of the implications of GDM on maternal-fetal health and the small number of investigations that relate the diet of pregnant women to the occurrence of the disease, the objective of this study was to evaluate the relationship between dietary patterns and GDM. Additionally, we analyzed the relationship between dietary patterns and excessive body weight, which is a convincing risk factor for GDM.

\section{METHODS}

\section{Study Design and Population}

A cross-sectional study was conducted with a convenience sample of 785 pregnant women users of the Unified Health System of Ribeirão Preto, state of São Paulo, between 2011 and 2012. The women were invited to participate in the study on the occasion of their oral glucose tolerance test in five laboratories that had an agreement with the Municipal Health Department, where there was higher demand for the examination. A follow-up scheme was established by trained nutritionists every day of the week. Women who met the inclusion criteria and agreed to participate in the study were interviewed. The study design was described in detail by Barbieiri et al. ${ }^{12}$.

The inclusion criteria of the study were: gestational age after the 24th week, age $\geq 20$ years and pre-gestational body mass index (BMI) $\geq 20 \mathrm{~kg} / \mathrm{m}^{2}$. Women with diabetes, those who reported usage of glucose-modifying drugs (such as glucocorticoids) and those with chronic renal failure, AIDS or cancer, were excluded.

Between the data collection period and the analysis of the results, there was a change in the diagnostic criteria ${ }^{13}$ and in the estimated prevalence of $\mathrm{GDM}^{14}$, and therefore the sample size was calculated a posteriori. Considering a prevalence of 20\% GDM among adult women ${ }^{14}$ and an acceptable margin of error of $5 \%$, the required sample size would be 512 women. A total of 1,446 pregnant women were contacted, of which 619 were excluded due to non-compliance with the study criteria, 19 did not agree to participate, 20 did not 
complete the examination and three presented incomplete data, totaling 785 women. Among them, $70 \%$ were interviewed between the $24^{\text {th }}$ and $28^{\text {th }}$ gestational weeks, and $30 \%$ between the $29^{\text {th }}$ and $39^{\text {th }}$.

At the time of the interview, the pregnant women were subjected to anthropometric evaluation and answered to a structured questionnaire with socioeconomic data, obstetric and family history, lifestyle and food consumption.

\section{Diagnosis of Gestational Diabetes Mellitus}

Fasting blood samples, one and two hours after ingestion of a $75 \mathrm{~g}$ glucose overload, were obtained from all study participants. Determination of glycemia was performed using the glucose oxidase test. Diagnosis of GDM was based on World Health Organization criteria of $2014^{13}$, which takes into account pregnant women with at least one of their glycemia values altered at any stage of pregnancy: fasting glycemia between 92 and $125 \mathrm{mg} / \mathrm{dl}$, glycemia one hour after glucose overload $\geq 180 \mathrm{mg} / \mathrm{dl}$ or glycemia two hours after glucose overload between 153 and $199 \mathrm{mg} / \mathrm{dl}$. Pregnant women who had fasting glycemia $\geq 126 \mathrm{mg} / \mathrm{dL}$ or two hours after glucose overload $\geq 200 \mathrm{mg} / \mathrm{dL}$ were considered to have previous diabetes and were excluded from the study analyses.

\section{Characteristics of Pregnant Women}

With use of a structured questionnaire, we obtained data on age, schooling, smoking history, family history of type 2 diabetes (DM), previous GDM, and practice of physical activities. The physical activity questionnaire used was previously developed and validated for pregnant women ${ }^{15}$. However, given the difficulty of the women in responding, for this study we consider only data related to the practice of walking for locomotion or during leisure, as well as the practice of physical exercises (in minutes per week).

Gestational age was estimated based on the date of the last menstruation (DLM). DLM and pre-gestational weight data were obtained from the record on the pregnant woman's card. At the time of the interview, measurements of weight (in kg) and height (in m) were acquired from a digital scale (TANITA model HS302) and a portable stadiometer (SANNY model ES2040), respectively. For the classification of BMI according to the gestational week, the criteria proposed by Atalah ${ }^{16}$ were adopted.

\section{Assessment of Food Consumption and Determination of Food Patterns}

Dietary intake was assessed by two 24-hour dietary recalls (R24h) obtained by trained nutritionists using the three-steps multiple pass technique (participant reporting, detailing, and review). The first R24h was obtained at the time of the interview and the second by telephone contact after at least seven days, regardless of the day of the week or season, and before the woman receives the results of biochemical exams.

The Brazilian Table of Food Composition (TACO) ${ }^{17}$ was used to estimate energy and nutrients. We analyzed the diets with the aid of the application software NutWin ${ }^{\circledR 18}$. In order to estimate the usual diet, we used the multiple source method ${ }^{19}$, a statistical modeling technique that considers the product between the probability of consumption and the usual intake ${ }^{19}$.

In total, 481 foods and preparations were reported in the R24h. Foods with less than $20 \%$ of consumers were excluded. Other foods and preparations were grouped into 23 groups of food (grams/day) based on the nutritional value or the logic of consumption: rice; beans; meat (red meat and chicken); fruits, vegetables; pasta; breads; butter and margarine; hard and soft cheese; cold meats (mortadella, turkey breast, ham, sausage, salami); milk and yogurt; chocolate milk and cappuccino; sugar; coffee and tea; candies (paçoca, pavês, pé de moleque, popsicle, ice cream, pie, candy, beijinho, brigadeiro, chocolate, cocada, doce de leite, flan, blancmange, maria mole, milkshake, mousse, hazelnut cocoa spread, panettone, doughnut, sonho, buttery biscuit, cake); natural fruit juice; artificial juice and soda; snacks, 
pizzas and sandwiches (fried and baked snacks, chips, sandwich, hot dog, pizza, popcorn and instant noodles); tubers; eggs; fish; olive oil; and biscuits.

Food patterns were identified by means of principal component analysis, which allows food groups to be grouped based on the degree of correlation between them. Negative factor loadings indicate that the variable is inversely associated with the factor and positive charges, wherein the food group is directly associated with the factor. To identify the number of patterns to be retained, we use eigenvalues $>1.5$. After orthogonal Varimax rotation, we kept the food groups with a factorial load $\geq 0.3$. In total, 18 food groups were retained within the food patterns. The tubers, eggs, fish, olive oil and biscuits groups presented low commonality and were excluded.

\section{Statistical Analysis}

Descriptive and comparative analyses of the study variables according to dietary pattern were performed using the chi-square test for categorical variables, and ANOVA and Kruskal-Wallis for continuous variables.

Adjusted multinomial logistic regression models were used to evaluate the association between adherence to dietary patterns (in tertile) with overweight and obesity, adopting the eutrophic women as reference. For such analyses, 31 women with low weight for their gestational week were excluded. We considered the following adjustment variables for the models: age (years), gestational week at the time of interview, education (years of study), smoking (never smoked, interrupted during gestation or currently smokes), physical activity practice (minutes/week walking or exercise) and number of children.

Adjusted logistic regression models were used to assess the association between adherence to dietary patterns and GDM. GDM (yes or no) was considered a dependent variable, and dietary patterns (in tertile) were considered independent variables. Model 1 was adjusted for: age (years), gestational week at the time of the interview, previous GDM (yes; no), schooling (years of study), family history of DM (yes; no), smoking (never smoked, interrupted during gestation, or currently smokes), physical activity (minutes/week of walking or exercise) and number of children. In Model 2, in addition to the variables included in Model 1, further adjustment for maternal excessive body weight (yes or no) was considered.

The selection of adjustment variables for the models was based on the theoretical reference of food consumption influence on the occurrence of maternal excessive body weight, as well as on GDM. However, variables considered the causal pathway between exposure and outcomes, such as dietary energy, were not taken into account. A value of $p<0.05$ was adopted as level of significance. The statistical analyses were performed with the aid of the application software IBM SPSS Statistics (version 24.0, SPSS Inc. Woking, Surrey, UK).

This study was approved by the Research Ethics Committee of the School and Health Center of the Ribeirão Preto Medical School, University of São Paulo (CEP/ CSE-FMRP-USP-023/2015) and its execution authorized by the Municipal Secretary of Health of Ribeirão Preto (2030/10 GS).

\section{RESULTS}

Among the 785 pregnant women investigated, 139 (17.7\%) had gestational diabetes, 261 (33.2\%) were classified as overweight and $187(23.8 \%)$ as obese.

Four dietary patterns were identified: "traditional Brazilian", "snacks", "coffee" and "healthy", which together accounted for about $41 \%$ of the variance, and the observed KMO was 0.56 . The "traditional Brazilian" pattern was characterized by consumption of rice; bean; meat; vegetables, and inversely associated with the consumption of hard and soft cheese; snacks, 
pizzas and sandwiches. The "snacks" patterns was characterized by the consumption of breads; butter and margarine; milk and yogurt; hard and soft cheese; sweets; chocolate milk and cappuccino. The "coffee" pattern was characterized by consumption of coffee; sugar, butter and margarine. The "healthy" pattern was characterized by the consumption of vegetables; fruit and natural fruit juice; and it was inversely associated with the consumption of soda and artificial juice (Table 1).

Women with greater adherence to the "traditional Brazilian" pattern reported lower schooling, more time spent in physical activities, and lower pre-gestational BMI than women with greater adherence. There was also a difference in smoking frequency and family history of type 2 diabetes. The pregnant women with greater adherence to the "snacks" pattern were younger and reported more schooling and less time practicing physical activities than pregnant women with lower adherence. Those with higher adherence to the "coffee" pattern presented higher average age, a higher number of children and lower schooling than those with lower adherence. And women with greater adherence to the "healthy" pattern had a higher average age and reported more time spent on physical activities than women with lower adherence (Table 2). However, some of these differences are not considered clinically relevant.

According to multinomial logistic regression models adjusted for age, gestational week at the time of the interview, schooling, smoking, number of children and physical activity, the pregnant women with greater adherence to the "traditional Brazilian" and "healthy" patterns showed less chance of obesity than those with lower adherence. Pregnant women classified as within the second tertile of adherence to the "snacks" pattern were more likely to be overweight than those in the first tertile, but this relationship was observed only at the intermediate level of adherence to the pattern (Table 3).

Table 1. Factor loading of the dietary patterns of pregnant women obtained by principal component analysis. Ribeirão Preto, state of São Paulo, 2011-2012. $(n=785)$

\begin{tabular}{lcccc}
\hline \multirow{2}{*}{ Food group (g/day) } & \multicolumn{3}{c}{ Feeding pattern } \\
\cline { 2 - 5 } & $\begin{array}{c}\text { Traditional } \\
\text { Brazilian }\end{array}$ & Snacks & Coffee & Healthy \\
\hline Rice & $\mathbf{0 . 8 1 1}$ & -0.014 & 0.015 & 0.015 \\
Beans & $\mathbf{0 . 7 3 8}$ & -0.042 & -0.024 & 0.125 \\
Meats (red meat and chicken) & $\mathbf{0 . 4 4 8}$ & 0.091 & -0.047 & -0.165 \\
Snacks, pizzas and sandwiches & $\mathbf{- 0 . 3 3 1}$ & 0.101 & -0.232 & -0.012 \\
Pasta & -0.291 & 0.155 & 0.118 & -0.290 \\
Breads & 0.159 & $\mathbf{0 . 7 1 8}$ & 0.299 & -0.049 \\
Butter and margarine & 0.222 & $\mathbf{0 . 5 4 7}$ & $\mathbf{0 . 3 2 1}$ & -0.145 \\
Cold meats & 0.221 & $\mathbf{0 . 4 6 7}$ & 0.026 & 0.037 \\
Milk and yogurt & 0.134 & $\mathbf{0 . 4 4 8}$ & $\mathbf{- 0 . 3 2 0}$ & 0.249 \\
Hard and soft cheese & $\mathbf{- 0 . 3 1 5}$ & $\mathbf{0 . 4 4 0}$ & -0.168 & 0.221 \\
Candies & -0.141 & $\mathbf{0 . 3 3 0}$ & -0.067 & -0.180 \\
Coffee and tea & 0.051 & 0.067 & $\mathbf{0 . 7 8 7}$ & -0.028 \\
Sugar & -0.009 & 0.134 & $\mathbf{0 . 6 5 1}$ & 0.114 \\
Chocolate milk and cappuccino & 0.101 & $\mathbf{0 . 4 6 7}$ & $\mathbf{- 0 . 5 2 0}$ & -0.080 \\
\hline Natural fruit juice & -0.185 & 0.083 & -0.070 & $\mathbf{0 . 6 1 6}$ \\
Vegetables & 0.383 & 0.048 & -0.046 & $\mathbf{0 . 5 7 6}$ \\
\hline Soda and artificial juice & 0.114 & 0.261 & -0.208 & $\mathbf{- 0 . 5 4 7}$ \\
Fruits & 0.021 & 0.022 & 0.074 & $\mathbf{0 . 5 4 4}$ \\
\hline Variance \% & 11.4 & 10.5 & 9.8 & 9.0 \\
Cumulative variance \% & 11.4 & 22.0 & 31.8 & 40.8 \\
\hline
\end{tabular}

${ }^{a}$ The foods whose factor loading is higher than 0.30 were kept in the matrix. Extraction method: principal component analysis. Rotation Method: Varimax with Kaiser normalization.

Factor loading values $\geq 0.3$ or $\leq-0.3$ are shown in bold. 
Table 2. Sociodemographic characteristics, anthropometric data and lifestyle according to dietary patterns during gestation. Ribeirão Preto, state of São Paulo, 2011-2012. $(\mathrm{n}=785)$

\begin{tabular}{|c|c|c|c|c|c|c|c|c|c|}
\hline \multirow[t]{2}{*}{ Mother characteristics } & \multirow[t]{2}{*}{ All } & \multicolumn{2}{|c|}{$\begin{array}{c}\text { Pattern } \\
\text { traditional Brazilian }\end{array}$} & \multicolumn{2}{|c|}{$\begin{array}{l}\text { Pattern } \\
\text { snack }\end{array}$} & \multicolumn{2}{|c|}{$\begin{array}{l}\text { Pattern } \\
\text { coffee }\end{array}$} & \multicolumn{2}{|c|}{$\begin{array}{l}\text { Pattern } \\
\text { healthy }\end{array}$} \\
\hline & & $1^{\text {st }}$ tercile & $3^{\text {rd }}$ tercile & $1^{\text {st }}$ tercile & $3^{\text {rd }}$ tercile & $1^{\text {st }}$ tercile & $3^{\text {rd }}$ tercile & $1^{\text {st }}$ tercile & $3^{\text {rd }}$ tercile \\
\hline \multirow[t]{2}{*}{ With GDM/normoglycemic } & $139 / 646$ & $58 / 203$ & $40 / 222$ & $48 / 213$ & $43 / 219$ & $43 / 218$ & $48 / 214$ & $45 / 216$ & $50 / 212$ \\
\hline & \multicolumn{9}{|c|}{$\mathrm{n}(\%)$} \\
\hline Previous GDM & $34(4.3)$ & $9(3.4)$ & $17(6.5)$ & $10(3.8)$ & $8(3.1)$ & $7(2.7)$ & $17(6.5)$ & $8(3.1)$ & $17(6.5)$ \\
\hline DM family history & $205(26.1)$ & $67(25.7)$ & $82(31.3)^{\mathrm{a}}$ & $77(29.5)$ & $70(26.7)$ & $74(28.4)$ & $62(23.7)$ & $67(25.7)$ & $74(28.2)$ \\
\hline Smoking during pregnancy & $71(9.0)$ & $16(6.1)$ & $33(12.6)$ & $26(10.0)$ & $24(9.2)$ & $20(7.7)$ & $29(11.1)$ & $26(10.0)$ & $18(6.9)$ \\
\hline \multicolumn{10}{|l|}{$\begin{array}{l}\text { BMI category according to } \\
\text { gestational age }\end{array}$} \\
\hline Low weight & $27(3.4)$ & $6(2.3)$ & $12(4.6)$ & $11(4.2)$ & $10(3.8)$ & $11(4.2)$ & $6(2.3)$ & $12(4.6)$ & $10(3.8)$ \\
\hline Eutrophia & $310(39.5)$ & $97(37.2)$ & $107(40.8)$ & $105(40.2)$ & $102(38.9)$ & $107(41.0)$ & $104(39.7)$ & $98(37.5)$ & $114(43.5)$ \\
\hline Overweight & $261(33.2)$ & $84(32.2)$ & $92(35.1)$ & $74(28.4)$ & $94(35.9)$ & $88(33.7)$ & $84(32.1)$ & $79(30.3)$ & $87(33.2)$ \\
\hline \multirow[t]{2}{*}{ Obesity } & $187(23.8)$ & $74(28.4)$ & $51(19.5)$ & $71(27.2)$ & $56(21.4)$ & $55(21.1)$ & $68(26.0)$ & $72(27.6)$ & $51(19.5)$ \\
\hline & \multicolumn{9}{|c|}{ Mean (SD) } \\
\hline Age (years) & $27.6(5.4)$ & $28.1(5.7)$ & $27.0(5.2)$ & $28.5(5.5)$ & $26.8(5.3)^{\mathrm{b}}$ & $26.4(4.8)$ & $28.5(5.8)^{b}$ & $26.7(5.1)$ & $28.6(5.8)^{\mathrm{b}}$ \\
\hline Schooling (years of study) & $9.2(2.7)$ & $9.6(2.6)$ & $8.9(2.7)^{\mathrm{b}}$ & $8.7(3.0)$ & $9.6(2.5)^{\mathrm{b}}$ & $9.5(2.3)$ & $8.9(2.9)^{b}$ & $9.0(2.5)$ & $9.3(2.8)$ \\
\hline Pre-gestational BMI $\left(\mathrm{kg} / \mathrm{m}^{2}\right)$ & $25.9(5.0)$ & $26.5(5.2)$ & $25.3(4.6)^{b}$ & $26.4(5.5)$ & $25.5(5.0)$ & $25.5(4.8)$ & $26.0(5.0)$ & $26.1(5.2)$ & $25.3(4.9)$ \\
\hline \multirow[t]{2}{*}{ Number of children } & $1.2(1.2)$ & $1.2(1.2)$ & $1.1(1.2)$ & $1.3(1.3)$ & $1.1(1.2)$ & $0.9(1.1)$ & $1.5(1.4)^{\mathrm{b}}$ & $1.2(1.3)$ & $1.2(1.2)$ \\
\hline & \multicolumn{9}{|c|}{ Median (P25; P75) } \\
\hline Physical activity $^{d}$ & $40(0 ; 140)$ & $35(0 ; 120)$ & $60(0 ; 150)^{c}$ & $50(0 ; 150)$ & $40(0 ; 120)^{c}$ & $40(0 ; 122)$ & $50(0 ; 140)$ & $40(0 ; 120)$ & $60(0 ; 150)^{c}$ \\
\hline
\end{tabular}

GDM: gestational diabetes mellitus; DM: diabetes mellitus; BMI: body mass index

${ }^{\text {a }} \mathrm{p}<0.05$, according to the $\mathrm{X}^{2}$ test.

${ }^{\mathrm{b}} \mathrm{p}<0.05$, according to ANOVA.

c $p<0.05$, according to the Kruskal-Wallis test.

${ }^{\mathrm{d}}$ Physical activity (minutes per week of walking or exercise).

Table 3. Association between dietary patterns during pregnancy with overweight and obesity. Ribeirão Preto, state of São Paulo, 2011-2012 ${ }^{\mathrm{a}}$ ( $(\mathrm{n}=754)$

\begin{tabular}{|c|c|c|c|c|c|}
\hline \multirow{2}{*}{ Variable } & \multirow{2}{*}{ 1st tercile } & \multicolumn{2}{|c|}{ 2nd tercile } & \multicolumn{2}{|c|}{ 3rd tercile } \\
\hline & & OR & $95 \% \mathrm{Cl}$ & OR & $95 \% \mathrm{Cl}$ \\
\hline \multicolumn{6}{|c|}{ Traditional Brazilian pattern } \\
\hline \multicolumn{6}{|l|}{ Overweight } \\
\hline Adjusted model $^{b}$ & 1.00 & 0.85 & $0.56-1.29$ & 1.06 & $0.70-1.60$ \\
\hline \multicolumn{6}{|l|}{ Obesity } \\
\hline Adjusted model $^{b}$ & 1.00 & 0.70 & $0.45-1.08$ & 0.61 & $0.38-0.96$ \\
\hline \multicolumn{6}{|c|}{ Snacks pattern } \\
\hline \multicolumn{6}{|l|}{ Overweight } \\
\hline Adjusted model $^{b}$ & 1.00 & 1.55 & $1.01-2.36$ & 1.40 & $0.92-2.15$ \\
\hline \multicolumn{6}{|l|}{ Obesity } \\
\hline Adjusted model $^{b}$ & 1.00 & 0.88 & $0.56-1.38$ & 0.86 & $0.55-1.35$ \\
\hline \multicolumn{6}{|c|}{ Coffee pattern } \\
\hline \multicolumn{6}{|l|}{ Overweight } \\
\hline Adjusted model $^{b}$ & 1.00 & 1.25 & $0.83-1.89$ & 1.13 & $0.75-1.72$ \\
\hline \multicolumn{6}{|l|}{ Obesity } \\
\hline Adjusted model $^{\mathrm{b}}$ & 1.00 & 1.27 & $0.81-2.00$ & 1.12 & $0.71-1.76$ \\
\hline \multicolumn{6}{|c|}{ Healthy pattern } \\
\hline \multicolumn{6}{|l|}{ Overweight } \\
\hline Adjusted model $^{\mathrm{b}}$ & 1.00 & 1.13 & $0.74-1.71$ & 0.84 & $0.55-1.29$ \\
\hline \multicolumn{6}{|l|}{ Obesity } \\
\hline Adjusted model $^{\mathrm{b}}$ & 1.00 & 0.89 & $0.57-1.38$ & 0.52 & $0.33-0.83$ \\
\hline
\end{tabular}

${ }^{a}$ Multinomial logistic regression models, considering eutrophic models as reference.

${ }^{b}$ Multinomial logistic regression models adjusted for age, gestational week at the time of interview, schooling (years of study), smoking (never smoked, interrupted during gestation, and currently smokes), physical activity practice (minutes/week of walking for locomotion or physical exercise) and number of children. 
Table 4. Relationship between dietary patterns during gestation and gestational diabetes mellitus. Ribeirão Preto, state of São Paulo, $2011-2012^{\mathrm{a}} \cdot(\mathrm{n}=785)$

\begin{tabular}{|c|c|c|c|c|}
\hline \multirow{2}{*}{ Variable } & \multirow{2}{*}{$1^{\text {st }}$ tercile } & $2^{\text {nd }}$ tercile & $3^{\text {rd }}$ tercile & \multirow{2}{*}{ p trend } \\
\hline & & OR $(95 \% \mathrm{CI})$ & OR $(95 \% \mathrm{CI})$ & \\
\hline \multicolumn{5}{|c|}{ Traditional Brazilian pattern } \\
\hline Model $1^{\mathrm{b}}$ & 1.00 & $0.64(0.41-1.02)$ & $0.62(0.39-0.99)$ & 0.04 \\
\hline Model $2^{c}$ & 1.00 & $0.66(0.41-1.05)$ & $0.64(0.39-1.04)$ & 0.06 \\
\hline \multicolumn{5}{|c|}{ Snacks pattern } \\
\hline Model $1^{\mathrm{b}}$ & 1.00 & $1.06(0.67-1.69)$ & $1.01(0.63-1.63)$ & 0.95 \\
\hline Model $2^{\mathrm{c}}$ & 1.00 & $1.00(0.63-1.61)$ & $0.96(0.59-1.55)$ & 0.88 \\
\hline \multicolumn{5}{|c|}{ Coffee pattern } \\
\hline Model $1^{\mathrm{b}}$ & 1.00 & $1.01(0.63-1.63)$ & $0.97(0.60-1.58)$ & 0.91 \\
\hline Model $2^{\mathrm{c}}$ & 1.00 & $1.00(0.63-1.63)$ & $0.97(0.59-1.59)$ & 0.92 \\
\hline \multicolumn{5}{|c|}{ Healthy pattern } \\
\hline Model $1^{\mathrm{b}}$ & 1.00 & $0.92(0.57-1.48)$ & $0.97(0.61-1.56)$ & 0.91 \\
\hline Model $2^{\mathrm{c}}$ & 1.00 & $0.91(0.57-1.47)$ & $1.04(0.64-1.68)$ & 0.87 \\
\hline
\end{tabular}

a Non-conditional logistic regression models, considering normoglycemic women as reference.

${ }^{b}$ Model 1 was adjusted for: age (years), gestational week at the time of the interview, previous GDM (yes/no), schooling (years of study), family history of DM (yes/no), smoking (never smoked, interrupted during gestation, or currently smokes), physical activity (minutes/week of walking or exercise) and number of children.

${ }^{c}$ Model 2: Additional adjustment for maternal excessive body weight (yes/no).

In non-conditional logistic regression models adjusted for age, gestational week at the time of the interview, schooling, previous GDM, family history of DM, smoking, number of children and physical activity, it was found that women with higher adherence to the "traditional Brazilian" had a lower chance of GDM. However, this association was not independent of maternal excessive body weight (Table 4).

\section{DISCUSSION}

In this study, pregnant women with greater adherence to the "healthy" and "traditional Brazilian" patterns presented a lower chance of obesity. On the other hand, women classified in the intermediate level of adherence to the "snacks" pattern presented a greater chance of being overweight. Regarding GDM, the findings suggest that maternal excessive body weight portrays relevant causality with respect to the inverse association between the "traditional Brazilian" dietary pattern and GDM.

The prevalence of obesity has been increasing exponentially, which can be partially attributed to changes in the population's eating behavior, where meal-based dietary patterns are replaced by those based on ready-to-eat industrialized products ${ }^{20}$. Our findings support this hypothesis, since women with greater adherence to the "traditional Brazilian" pattern, composed of typical food markers for meals, such as rice, beans, meats, vegetables, characterized by a lower consumption of snacks, pizzas and sandwiches, presented a lower chance of obesity.

The inverse association between adherence to the "healthy" pattern and obesity in pregnant women corroborates the scientific evidence of a possible protective effect of food intake with adequate nutrient intake and low caloric density in the energy balance. Fruits, vegetables are also high in fiber, which have the capacity to reduce gastric emptying time and promote satiet $^{21}$. Moreover, the "healthy" pattern was inversely associated with the consumption of soda and artificial juices, which are considered relevant risk factors for obesity due to their high sugar content, high glycemic index and, consequently, low satiety capability. Sugary drinks are rapidly absorbed by the body and do not stimulate the signs of satiety in the same way as solid foods. Moreover, they are ineffective in stimulating insulin production, one of 
the physiological signals for energy balance ${ }^{22}$. In addition, women with greater adherence to "traditional Brazilian" and "healthy" patterns reported longer walking and exercise time, which could contribute to a greater energy expenditure and adequate weight maintenance ${ }^{23}$; however, the associations were independent of physical activity practice.

The positive association found between the "snack" pattern and overweight is consistent with the literature ${ }^{24,25}$. However, in this study, this association was significant only for the second tertile, compared to the first. The "snacks" pattern consisted of breads, butter and margarine, cold meats, hard and soft cheese, and sweets, which suggests a pattern of food substitution from main meals to snacks. Frequent consumption of these foods with high energy density can lead to damage in the neuronal circuits involved with the regulation of appetite and satiety ${ }^{26}$.

Obesity is considered a significant risk factor for GDM. The accumulation of body fat, associated with physiological changes mediated by placental hormones in pregnancy, can increase insulin resistance and predisposition to GDM. It is known that DMG is due to both exacerbated insulin resistance and previous dysfunction of $\beta$-cells ${ }^{27}$. In this study, adjustment for maternal excessive body weight attenuated the association between the "traditional Brazilian" pattern and GDM.

Studies that investigated the relationship between dietary patterns during pregnancy and GDM are scarce and were conducted in regions with different eating habits to Brazilian culture, limiting the comparison of the findings ${ }^{3,6,9,10,19,28}$. A cohort study conducted in Singapore among 909 pregnant women showed that women with higher adherence to a pattern rich in vegetables, fruits, white rice, meats and fish with low consumption of potato chips, hamburgers and sugary drinks had a lower chance of GDM ${ }^{10}$. This pattern consists of some foods found in the "traditional Brazilian" and "healthy" standards of this study; however, these patterns were not related to the outcome.

Among the results of the study, a higher proportion of women with GDM were classified as within the highest tertile of the "healthy" pattern, which was not expected and cannot be explained in the literature. One of the hypotheses of the present study was an inverse association between adherence to the "healthy" pattern and GDM, which was not confirmed. According to the literature, the results are controversial ${ }^{6,9,10,29}$. It is suggested that dietary patterns rich in fruits and vegetables have a protective effect on the development of diseases such as GDM, given the low energy density, glycemic load and the high antioxidant and phytochemical content of these foods ${ }^{21}$. However, dietary habits are specific to each population, with different ethnicities and genetic predispositions, which could partially explain the disagreement between studies. Exposure to modifiable risk factors during the pre-gestational period, which was not considered in the present study, may also have influenced the results found.

A possible justification for the lack of association between the "healthy" and "snack" patterns and the outcomes analyzed is the fact that these food consumption patterns are more subject to social desirability bias. One study showed that individuals with higher social desirability tend to report higher consumption of fruits, vegetables, and lower food intake of breads and biscuits, thus attenuating associations ${ }^{30}$.

One cannot ignore the hypothesis that a voluntary change in food consumption may occur during pregnancy in order to promote the growth and development of the baby. However, the evidence regarding dietary changes in this life cycle is controversial ${ }^{31}$.

Evaluating dietary intake through analysis of dietary patterns is considered an adequate strategy, since it contemplates the diet as a whole, supplying the limitation of approaches that evaluate nutrients and food items alone ${ }^{7.8}$. Among the strengths of the study, we highlight the use of the multiple source metho $d^{19}$ for the estimation of the usual diet, and the use of the World Health Organization criteria from $2014^{13}$ for the diagnosis of GDM, which were accepted by the International Federation of Gynecology and Obstetrics ${ }^{32}$. The 
main limitation of the study is its cross-sectional design, which made it impossible to identify a temporal relationship between dietary patterns and the outcomes investigated. Reverse causality may also have occurred, since $46 \%$ of the pregnant women evaluated had excessive body weight during the pre-gestational period. However, neither the pregnant women nor the interviewers knew the results of the diagnostic test for GDM at the time of the interview, which reduced the chance of information bias in the investigation of this outcome. Data on weight gain during the first trimester of pregnancy were not collected, which made it impossible to estimate the adequacy of weight gain; thus, the models were adjusted for excessive body weight according to gestational age as an indicator of both pre-gestational excessive body weight and excessive weight gain. Social desirability was not investigated in this study, making it impossible to confirm the hypothesis of reporting bias. Another limitation inherent to studies evaluating dietary data is a possible underreporting of dietary intake. In addition, the use of logistic regression in cross-sectional studies whose outcome is highly prevalent has been criticized by some authors. However, this measure of association was used because it is recommended for cross-sectional studies investigating the effect of an exploratory variable on the occurrence of a health outcome ${ }^{33}$. The data presented here suggest a lower chance of obesity among pregnant women with greater adherence to "traditional Brazilian" and "healthy" patterns. There was no association between dietary patterns and GDM regardless of maternal excessive body weight. Prospective studies are recommended to investigate the relationship between dietary patterns and excessive body weight and GDM, reducing the chance of reverse causality.

\section{REFERENCES}

1. American Diabetes Association. Standards of Medical Care in Diabetes 2017. Diabetes Care. 2017;40 Suppl 1:S11- 24.

2. Sociedade Brasileira de Diabetes. VI Diretrizes da Sociedade Brasileira de Diabetes 2015- 2016. São Paulo: SBD; 2016.

3. Schoenaker DAJM, Mishra GD, Callaway LK, Soedamah-Muthu SS. The role of energy, nutrients, foods, and dietary patterns in the development of gestational diabetes mellitus: a systematic review of observational studies. Diabetes Care. 2016;39(1):16-23. https://doi.org/10.2337/dc15-0540

4. International Diabetes Federation. Diabetes atlas. 7. ed. Brussels (BE): IDF; 2015.

5. Scientific Advisory Committee on Nutrition. The influence of maternal, fetal and child nutrition on the development of chronic disease in later life. London: TSO; 2011 [cited 2018 Apr 14]. Available from: https://www.gov.uk/government/uploads/system/uploads/attachment_data/ file/339325/SACN_Early_Life_Nutrition_Report.pdf

6. Chen X, Zhao D, Mao X, Xia Y, Baker PN, Zhang H. Maternal dietary patterns and pregnancy outcome. Nutrients. 2016;8(6):351. https://doi.org/10.3390/nu8060351

7. Cespedes EM, Hu FB. Dietary pattern: from nutritional epidemiologic analysis to national guidelines. Am J Clin Nutr. 2015;101(5):899-900. https://doi.org/10.3945/ajcn.115.110213

8. Wirfält E, Drake I, Wallstrom P. What do review papers conclude about food and dietary pattern? Food Nutr Res. 2013;57. https://doi.org/10.3402/fnr.v57i0.20523

9. He JR, Yuan MY, Chen NN, Lu JH, Hu CY, Mai WB, et al. Maternal dietary patterns and gestational diabetes mellitus: a large prospective cohort study in China. Br J Nutr. 2015;113(8):1292-300. https://doi.org/ 10.1017/S0007114515000707

10. Seymour J, Chia A, Colega M, Jones B, McKenzie E, Shirong C, et al. Maternal dietary patterns and gestational diabetes mellitus in a multi-ethnic Asian cohort: The GUSTO study. Nutrients. 2016;8(9):E574. https://doi.org/10.3390/nu8090574

11. Shin D, Lee KW, Song WO. Dietary patterns during pregnancy are associated with risk of gestational diabetes mellitus. Nutrients. 2015;7(11):9369-82.

https://doi.org/10.3390/nu7115472 
12. Barbieiri P, Nunes JC, Torres AG, Nishimura RY, Zuccolotto DC, Crivellenti LC, et al. Indices of dietary fat quality during midpregnancy is associated with gestational diabetes. Nutrition. 2016;32(6):656-61. https://doi.org/10.1016/j.nut.2015.12.002

13. World Health Organization. Diagnostic criteria and classification of hyperglycemia first detected in pregnancy: a World Health Organization guideline. Diabetes Res Clin Pract. 2014;103(3):341-63. https://doi.org/10.1016/j.diabres.2013.10.012

14. Trujillo J, Vigo A, Reichelt A, Duncan BB, Schmidt MI. Fasting plasma glucose to avoid a full OGTT in the diagnosis of gestational diabetes. Diabetes Res Clin Pract. 2014;105(3):322-6. https://doi.org/10.1016/j.diabres.2014.06.001

15. Takito MY, Neri LCL, Benício MSA. Avaliação da reprodutibilidade e validade de questionário de atividade física para gestante. Rev Bras Med Esporte. 2008;14(2):132-8. https://doi.org/10.1590/S1517-86922008000200010:132-8

16. Atalah Samur E, Castillo-L C, Castro Santoro R, Aldea-P A. Propuesta de un nuevo estándar de evaluación nutricional en embarazadas. Rev Med Chile. 1997;125(12):1429-36.

17. Universidade Estadual de Campinas, Núcleo de Estudos e Pesquisas em Alimentação. Tabela brasileira de composição de alimentos - TACO. 2.ed. Campinas: NEPA; 2006. Available from: http://www.crn1 .org.br/wp-content/uploads/2015/04/taco.pdf?x53725

18. Anção MS, Cuppari L, Daibe AS, Sigulem D. Programa de Apoio à Nutrição - NutWin, versão 1.5. são Paulo: Departamento de Informática em saúde. UNIFESP/EPM: 2002.

19. Harttig U, Haubrock J, Knüppel S, Boeing H; EFCOVAL Consortium. The MSM program: web-based statistics package for estimating usual dietary intake using the Multiple Source Method. Eur J Clin Nutr. 2011;65 Suppl 1:S87-91. https://doi.org/10.1038/ejcn.2011.92

20. Monteiro CA, Cannon G, Maubarac JC, Levy RB, Louzada MLC, Jaime PC. The UN Decade of Nutrition, the NOVA food classification and the trouble with ultra-processing. Public Health Nutr. 2017;21(1):5-17. https://doi.org/10.1017/S1368980017000234

21. Zhang C, Liu S, Solomon CG, Hu FB. Dietary fiber intake, dietary glycemic load, and the risk for gestational diabetes mellitus. Diabetes Care. 2006;29(10):2223-30. https://doi.org/10.2337/dc06-0266

22. Woodward-Lopez G, Kao J, Ritchie L. To what extent have sweetened beverages contributed to the obesity epidemic? Public Health Nutr. 2010;14(3):499-509. https://doi.org/10.1017/S1368980010002375

23. Wall CR, Gammon CS, Bandara DK, Grant CC, Carr PEA, Morton SMB. Dietary patterns in pregnancy in New Zealand: influence of maternal socio-demographic, health and lifestyle factors. Nutrients. 2016;8(5):E300. https://doi.org/10.3390/nu8050300

24. Rohatgi KW, Tinius RA, Cade WT, Steele EM, Cahill AG, Parra DC. Relationships between consumption of ultra-processed foods, gestational weight gain and neonatal outcomes in a sample of US pregnant women. Peer J. 2017;5:e4091. https://doi.org/10.7717/peerj.4091

25. Uusitalo U, Arkkola T, Ovaskainen ML, Kronberg-Kippilä C, Kenward MG, Veijola $\mathrm{R}$, et al. Unhealthy dietary patterns are associated with weight gain during pregnancy among Finnish women. Public Health Nutr. 2009;12(12):2392-9. https://doi.org/10.1017/S136898000900528X

26. Lamyian M, Hosseinpour-Niazi S, Mirmiran P, Banaem LM, Goshtasebi A, Azizi F. Pre-pregnancy fast food consumption is associated with gestational diabetes mellitus among Tehranian women. Nutrients. 2017;9(3):E216. https://doi.org/10.3390/nu9030216

27. Ashwal E, Hod M. Gestational diabetes mellitus: where are we now? Clin Chim Acta. 2015;451(Pt A):14-20. https://doi.org/10.1016/j.cca.2015.01.021

28. Tryggvadotir EA, Medek H, Birgisdottir BE, Geirsson RT, Gunnarsdottir I. Association between healthy maternal dietary pattern and risk for gestational diabetes mellitus. Eur J Clin Nutr. 2016;70(2):237-42. https://doi.org/10.1038/ejcn.2015.145

29. Flynn AC, Seed PT, Patel N, Barr S, Bell R, Briley AL, et al. Dietary patterns in obese pregnant women; influence of behavioral intervention of diet and physical activity in the UPBEAT randomized controlled trial. Int J Behav Nutr Phys Act. 2016;13(1):124. https://doi.org/10.1186/s12966-016-0450-2

30. Barros R, Moreira P, Oliveira B. Influência da desejabilidade social na estimativa da ingestão alimentar obtida através de um questionário de frequência de consumo alimentar. Acta Med Port. 2005;18(4):241-7. 
31. Hillier SE, Olander EK. Women's dietary changes before and during pregnancy: a systematic review. Midwifery. 2017;49:19-31. https://doi.org/10.1016/j.midw.2017.01.014

32. Hod M, Kapur A, Sacks DA et al. The International Federation of Gynecology and Obstetrics (FIGO) Initiative on gestational diabetes mellitus: A pragmatic guide for diagnosis, management, and care. Int J Gynecol Obstet. 2015;131:173- 272. https://doi.org/10.1016/S0020-7292(15)30007-2

33. Reichenheim ME, Coutinho ESF. Measures and models for causal inference in cross-sectional studies: arguments for the appropriateness of the prevalence odds ratio and related logistic regression. BMC Med Res Methodol. 2010;10:66. https://doi.org/10.1186/1471-2288-10-66

Funding: Research grant CNPq (Conselho Nacional de Desenvolvimento Científico e Tecnológico, Process: 302498/2015-0 and 472221/2010-8), FAEPA (Fundação de Apoio ao Ensino, Pesquisa e Assistência do Hospital das Clínicas da Faculdade de Medicina de Ribeirão Preto da Universidade de São Paulo) and USP (Pró-Reitoria de Pesquisa da Universidade de São Paulo). Doctoral scholarship DCCZ and LCC CAPES (Coordenação de Aperfeiçoamento de Pessoal de Nível Superior).

Authors' Contributions: Conception and planning of the study: DCCZ, LCC, LJF, DSS. Data collection: DCCZ, LCC. Data analysis and interpretation: DCCZ, LCC, LJF, DSS. Manuscript elaboration: DCCZ, DSS. Manuscript revision and approval of final version: LCC, DCCZ, LJF, DSS. Public responsibility for the content of the article: DCCZ, LCC, LJF, DSS.

Conflict of Interest: The authors declare no conflicts of interest. 